\title{
A Chemical Model for Barium Oxide Depletion from Hollow Cathode's Insert
}

\author{
M. Coletti ${ }^{*}$ and S.B. Gabriel ${ }^{\dagger}$ \\ University of Southampton, Southampton, United Kingdom,SO17 1BJ
}

\begin{abstract}
In this paper a chemical model to predict barium oxide depletion from hollow cathode insert is developed. This model is based on the knowledge of the ternary diagram that exists in the $\mathrm{BaO}-\mathrm{CaO}-\mathrm{Al}_{2} \mathrm{O}_{3}$ system. This model takes also into account the diffusive motion of barium oxide inside the insert. A comparison between numerical and experimental data is made to determine the diffusion coefficient inside the insert. The diffusion coefficient presents an Arrhenius trend with activation energy similar to the one of barium oxide evaporation. A two dimensional model is used to demonstrate how temperature profile along the insert is a key parameter to calculate barium depletion.
\end{abstract}

\section{Nomenclature}

$=\mathrm{Al}_{2} \mathrm{O}_{3}$

$=\mathrm{BaO}$

$=\mathrm{CaO}$

$=$ diffusion coefficient

$=$ insert thickness

$=$ molecular mass

$=$ mass flow rate

$=$ number of reactions that produce barium

$=$ pressure

$=$ universal gas constant

$=$ temperature

$=$ time

$=$ molar fraction

$=$ coordinate

$=$ coordinate

$=$ reaction enthalpy

$=$ reaction entropy

$=$ density

$=$ diffusion characteristic time

Subscript

,$t=$ partial derivative relative to time

,$x \quad=$ partial derivative relative to $\mathrm{x}$

\section{Introduction}

$\mathrm{H}$ OLLOW cathodes are one of the most important components in the electric propulsion field. They are used as electron source and neutralizer inside ion thruster and Hall's effect thrusters and in the next future probably as stand alone microthrusters ${ }^{1}$ so their lifetime and performance are key elements in all the application mentioned

${ }^{*}$ PhD student, Astronautic Research Group, School of Engineering Sciences, University of Southampton, SO17 1BJ Southampton U.K. coletti@ soton.ac.uk

${ }^{\dagger}$ Professor of Aeronautics and Astronautics and Head of the Astronautic Research Group, Astronautic Research Group, School of Engineering Sciences, University of Southampton, SO17 1BJ Southampton U.K. sbg2@ soton.ac.uk 
above. The most important life limiting mechanism in hollow cathodes is depletion of low work function elements from the insert.

In this paper is presented a chemical model for barium oxide depletion from inserts impregnated with $\mathrm{BaO}-\mathrm{CaO}-$ $\mathrm{Al}_{2} \mathrm{O}_{3}$. This model is based on the knowledge of the ternary system composed by barium oxide, calcium oxide and alumina and takes into account how barium depletion is dependent from diffusion inside the insert and from the way barium oxide molecules alloy with calcium oxide and alumina ${ }^{2-5}$, aspects that are too frequently neglected in hollow cathodes lifetime studies.

\section{Chemical Model}

Barium depletion from the insert is the result of the complex chemistry of the $\mathrm{BaO}-\mathrm{CaO}-\mathrm{Al}_{2} \mathrm{O}_{3}$ ternary system so its knowledge and understanding is the basis for the development of a depletion model. The ternary diagram of the $\mathrm{BaO}-\mathrm{CaO}-\mathrm{Al}_{2} \mathrm{O}_{3}$ system is shown in Fig 1,2 .

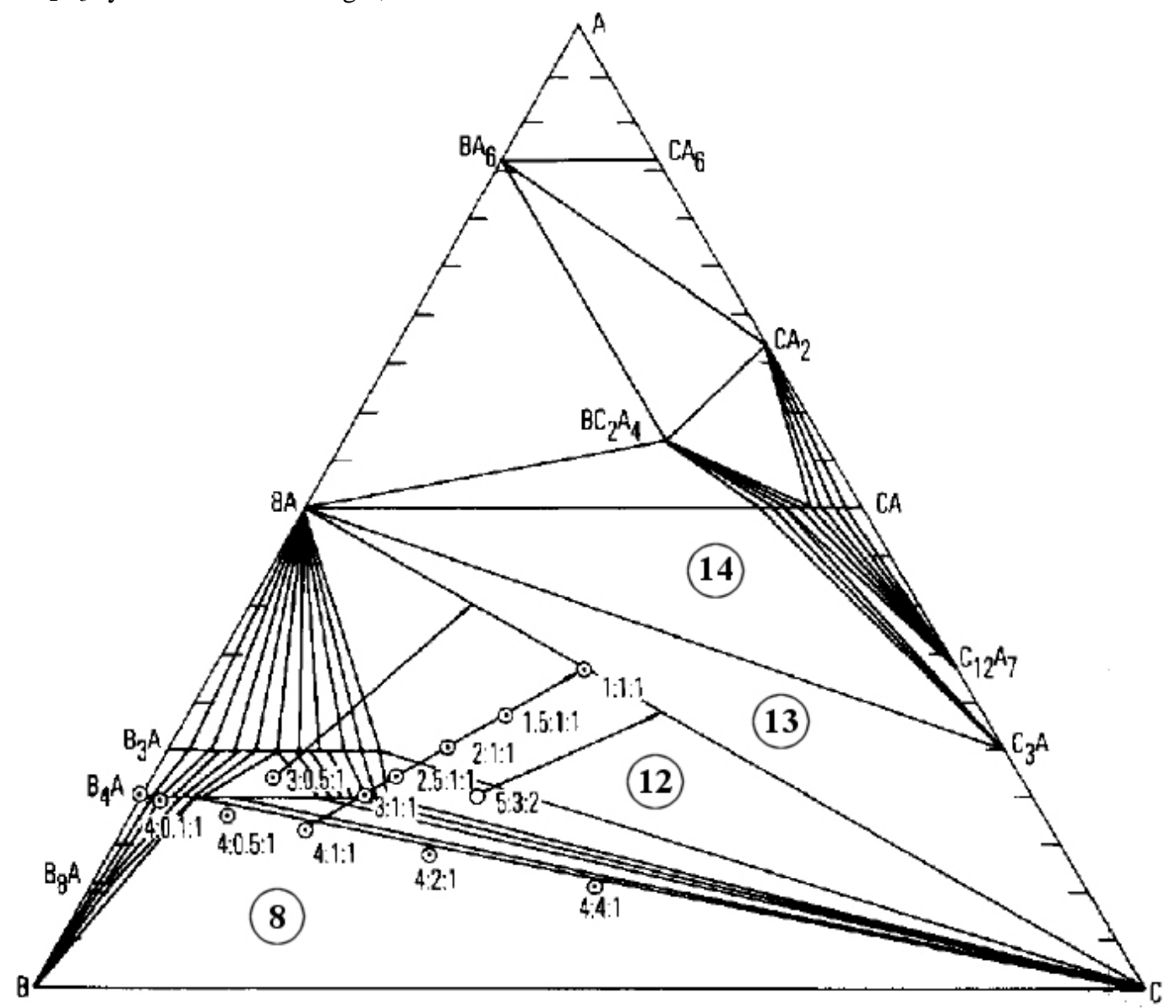

Figure 1. BaO-CaO-Al2O3 phase diagram at $1250{ }^{\circ} \mathrm{C}^{3}$

In this diagram the letters $\mathrm{A}, \mathrm{B}$ and $\mathrm{C}$ stand for $\mathrm{Al}_{2} \mathrm{O}_{3}, \mathrm{BaO}$ and $\mathrm{CaO}$ respectively. Each of the three corners represents a mass concentration of $100 \%$ of one of these three fundamental compounds (the one displayed near the corner).

Each point of the diagram represents a state of the system where the concentration of A, B and C are inversely proportional to the distance of the point from each corner. 


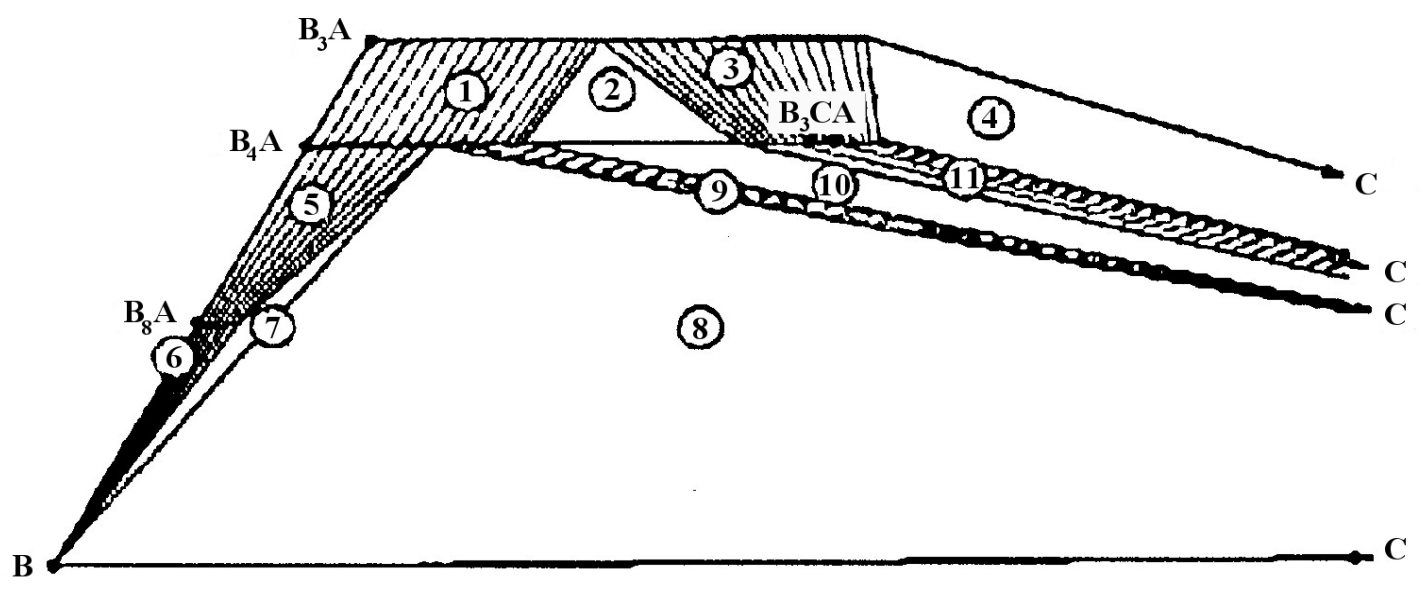

Figure 2. Particular of the $\mathrm{BaO}-\mathrm{CaO}-\mathrm{Al} 2 \mathrm{O3}$ phase diagram ${ }^{2}$

Each of the areas in which the diagram is divided represents a particular state of the system i.e. which compounds are present.

The empty areas stand for states in which the compounds stoichiometric coefficients are fixed while the filled ones stand for states in which the stoichiometric coefficients changes with the composition.

In most of these compounds we can find that the barium oxide can be partially substituted by calcium oxide because of their similar atomic configuration, when this happens we will refer to these compounds as solid solution (s.s.).

For example the expression $B_{4-x} C_{x} A$ means that in the $\mathrm{B}_{4} \mathrm{~A}$ compound $\mathrm{x}$ molecules of barium oxide have been substituted by calcium oxide.

Below there is a list of all the compounds present in the most important areas of the diagram ${ }^{2}$

\begin{tabular}{|c|c|c|c|}
\hline${\text { Area } \mathrm{N}^{\circ}}^{\circ}$ & Compounds & ${\text { Area } \mathrm{N}^{\circ}}^{\circ}$ & Compounds \\
\hline 1 & $\mathrm{~B}_{3} \mathrm{~A}$ s.s. and $\mathrm{B}_{4} \mathrm{~A}$ s.s. & 8 & $\mathrm{~B}, \mathrm{C}$ and $\overline{\mathrm{B}_{4} \mathrm{~A}}$ s.s. \\
\hline 2 & $\overline{\mathrm{B}_{3} \mathrm{~A}}$ s.s., $\overline{\mathrm{B}_{4} \mathrm{~A}}$ s.s. and $\overline{\mathrm{B}_{3} \mathrm{CA}}$ & 9 & $\mathrm{C}$ and $\overline{\mathrm{B}_{4} \mathrm{~A}}$ s.s. \\
\hline 3 & $\mathrm{~B}_{3} \mathrm{~A}$ s.s. and $\mathrm{B}_{3} \mathrm{CA}$ s.s. & 10 & $\mathrm{C}, \overline{\mathrm{B}_{4} \mathrm{~A}}$ s.s. and $\overline{\mathrm{B}_{3} \mathrm{CA}}$ s.s. \\
\hline 4 & $\mathrm{C}, \overline{\mathrm{B}_{3} \mathrm{~A}}$ s.s. and $\mathrm{B}_{3} \mathrm{CA}$ s.s. & 11 & $\mathrm{C}$ and $\overline{\mathrm{B}_{3} \mathrm{CA}}$ s.s \\
\hline 5 & $\mathrm{~B}_{4} \mathrm{~A}$ s.s. and $\mathrm{B}_{8} \mathrm{~A}$ s.s. & 12 & $\mathrm{C}, \mathrm{B}_{3} \mathrm{~A}$ and $\mathrm{BA}$ \\
\hline 6 & $\mathrm{~B}$ and $\mathrm{B}_{8} \mathrm{~A}$ s.s. & 13 & $\mathrm{C}, \mathrm{BA}$ and $\mathrm{C}_{3} \mathrm{~A}$ \\
\hline 7 & $\overline{\mathrm{B}, \overline{\mathrm{B}_{4} \mathrm{~A}}}$ s.s. and $\overline{\mathrm{B}_{8} \mathrm{~A}}$ s.s. & 14 & $\mathrm{AB}, \mathrm{C}_{3} \mathrm{~A}$ and $\mathrm{CA}$ \\
\hline
\end{tabular}

Once we know which compounds are present and which are their stoichiometric coefficients, using the conservation of atomic species we can calculate the final composition.

For example a 2:1:1 composition (that in mass fraction corresponds to: $50 \% \mathrm{BaO}, 25 \% \mathrm{CaO}, 25 \% \mathrm{Al}_{2} \mathrm{O}_{3}$ ) corresponds to area number 12 of the diagram so the compounds present are $\mathrm{C}, \mathrm{B}_{3} \mathrm{~A}$ and $\mathrm{BA}$.

Using the conservation of atomic species the final composition is found to be $2 \mathrm{C}+\mathrm{B}_{3} \mathrm{~A}+\mathrm{BA}$ or the equivalent $2 \mathrm{CaO}+\mathrm{Ba}_{3} \mathrm{Al}_{2} \mathrm{O}_{6}+\mathrm{BaAl}_{2} \mathrm{O}_{4}$.

For any other explanation about the ternary diagram refers to Ref. 2-4.

As can be easily inferred barium oxide evaporation is strongly dependent on which compounds are present on the surface and so on the local composition ${ }^{3,5}$ 
AIAA-2007-5193

\begin{tabular}{||c|c|c||}
\hline \multicolumn{2}{|c|}{ Table 2 Most important reaction in barium oxide evaporation } \\
\hline \hline Reactions & $\Delta H[\mathrm{eV}]$ & $\Delta S[\mathrm{~J} / \mathrm{mol}]$ \\
\hline $\mathrm{BaO}(\mathrm{s}) \rightarrow \mathrm{BaO}(\mathrm{g})$ & 4.3224 & 137.85 \\
\hline $1 / 5 \mathrm{Ba}_{8} \mathrm{Al}_{2} \mathrm{O}_{11}(\mathrm{~s}) \rightarrow \mathrm{BaO}(\mathrm{g})+1 / 4 \mathrm{Ba}_{4} \mathrm{Al}_{2} \mathrm{O}_{7}(\mathrm{~s})$ & 4.4267 & 130.72 \\
\hline $\mathrm{Ba}_{4} \mathrm{Al}_{2} \mathrm{O}_{7}(\mathrm{~s}) \rightarrow \mathrm{BaO}(\mathrm{g})+\mathrm{Ba}_{3} \mathrm{Al}_{2} \mathrm{O}_{6}(\mathrm{~s})$ & 4.5789 & 122.76 \\
\hline $1 / 2 \mathrm{Ba}_{3} \mathrm{Al}_{2} \mathrm{O}_{6}(\mathrm{~s}) \rightarrow \mathrm{BaO}(\mathrm{g})+1 / 2 \mathrm{BaAl}_{2} \mathrm{O}_{4}(\mathrm{~s})$ & 4.6615 & 125.28 \\
\hline $6 / 5 \mathrm{BaAl}_{2} \mathrm{O}_{4}(\mathrm{~s}) \rightarrow \mathrm{BaO}(\mathrm{g})+1 / 5 \mathrm{BaAl}_{12} \mathrm{O}_{19}(\mathrm{~s})$ & 5.6095 & 124.86 \\
\hline & & $\Delta S[\mathrm{~J} / \mathrm{mol}]$ \\
\hline $\mathrm{Decomposition} \mathrm{of} \mathrm{solid} \mathrm{solution}^{|c|}$ & $\Delta H[\mathrm{eV}]$ & 130.47 \\
\hline $\mathrm{Ba}_{8-0.2} \mathrm{Ca}_{0.2} \mathrm{Al}_{2} \mathrm{O}_{11}$ & 4.4267 & 122.05 \\
\hline $\mathrm{Ba}_{4-1.1 .1} \mathrm{Ca}_{1.1} \mathrm{Al}_{2} \mathrm{O}_{7}$ & 4.5789 & 122.93 \\
\hline $\mathrm{Ba}_{3-0.75} \mathrm{Ca}_{0.75} \mathrm{Al}_{2} \mathrm{O}_{6}$ & 4.6615 & \\
\hline
\end{tabular}

The calculation of barium oxide evaporation consists of four steps:

1) Given the concentration of $\mathrm{BaO}, \mathrm{CaO}$ and $\mathrm{Al}_{2} \mathrm{O}_{3}$, referring to the diagram in Errore. L'origine riferimento non è stata trovata.Errore. $L$ 'origine riferimento non è stata trovata.1,2 and to Errore. L'origine riferimento non è stata trovata., the compounds present can be determined and their concentration can be obtained

2) Using the data in Errore. L'origine riferimento non è stata trovata. the barium oxide pressure (in atmospheres) generated by each compound can be calculated as

$$
p_{B a O}=e^{-\frac{q \Delta H_{i}}{k T}+\frac{\Delta S_{i}}{R}}
$$

where the index $i$ is used to label the pressure relative to the $i$-th compound.

The final barium oxide pressure can be calculated as

$$
p_{\text {BaO }} \text { tot }=\sum_{i=1}^{N} p_{B a O_{i}} X_{i}
$$

where $X_{i}$ represent the molar fraction of the $i$-th compound.

4) The barium oxide mass flow rate per unit area can be obtained using the Knudsen-Hertz-Langmuir formula

$$
\dot{m}_{B a O}=\frac{p_{B a O_{t o t}}}{\sqrt{\frac{2 \pi R T}{M_{B a O}}}} \cdot 10^{5}
$$

So if we assume to start with a 4:1:1 composition we can calculate how the barium oxide pressure and the mass flow rate for unit area behave with barium content. 

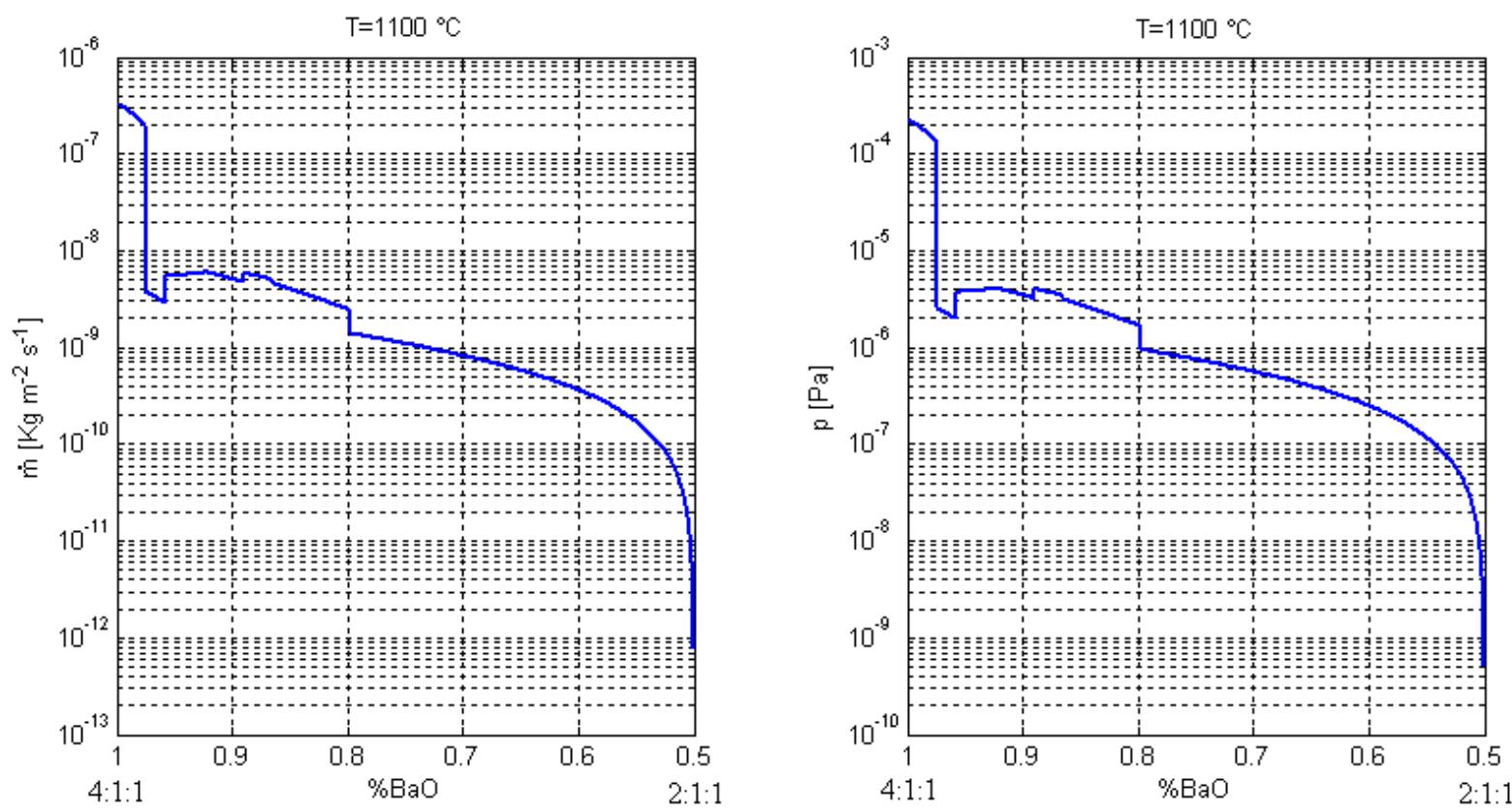

Figure 3. Barium oxide pressure and mass flow rate trend with barium content

As we can see in Fig. 3 the trend is strongly nonlinear and there are several order of magnitude of difference between the $\mathrm{BaO}$ pressure and evaporation rate of a 4:1:1 composition and the ones of a 2:1:1.

Hence the only way to evaluate barium depletion from the insert is to know with the highest possible precision which compounds are present on the surface.

This can be made using the ternary diagram and the reaction given above, calculating at each time which compounds are present and their concentrations and coupling this with a model for barium transfer from the inner part of the insert to the surface..

\section{One Dimensional Model}

Once we have understood how to use the diagram in Fig.1 we can develop our insert model.

Assume to have a one-dimensional insert impregnated with a 4:1:1 mixture of barium calcium aluminates like in Fig.4

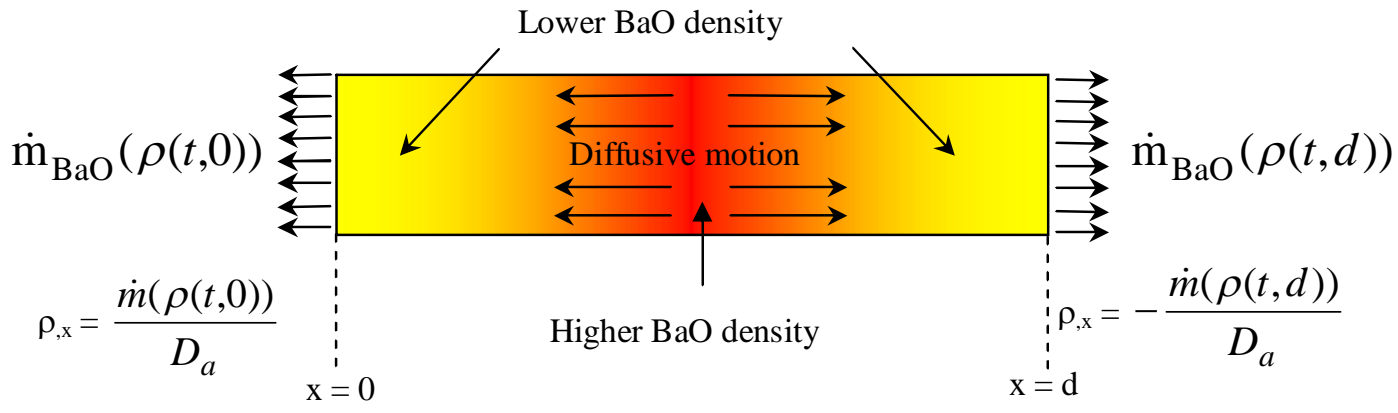

.Figure 4 - One dimensional insert model

Due to the high temperature of the insert we have barium oxide evaporation from the free surfaces; this causes a barium density gradient that gives rise to a diffusive motion of barium oxide inside the insert from its inner part towards the emitting surface. Hence the problem that we have to solve is a diffusion problem where the evaporation at the free surface is one of the two boundary conditions.

Using formulas we have 


$$
\begin{gathered}
\frac{\partial \rho}{\partial t}-D_{a} \frac{\partial^{2} \rho}{\partial x^{2}}=0 \\
\rho(t=0, x)=\rho_{0} \\
\rho_{, x}(t, x=0)=0 \\
\rho_{, x}(t, x=d)=-\frac{\dot{m}}{D_{a}}
\end{gathered}
$$

This system is strongly nonlinear because one of the boundary condition depends on the solution itself through the presence of the mass flow rate. Due to this strong nonlinearity no analytical solution exists so the system has been solved with an explicit finite difference method. The derivate with respect to space and time are

$$
\begin{gathered}
\frac{\partial^{2} \rho_{i}^{t}}{\partial x^{2}}=\frac{\rho_{i+1}^{t}-2 \rho_{i}^{t}+\rho_{i+1}^{t}}{\Delta x^{2}} \\
\frac{\partial \rho_{i}^{t}}{\partial t}=\frac{\rho_{i}^{t+1}-\rho_{i}^{t}}{\Delta t}
\end{gathered}
$$

The system has been made dimensionless using the insert thickness $L$ as characteristic length and defining the characteristic time to make the diffusion coefficient disappear, so the density at the time step $\mathrm{t}+1$ is calculated as

$$
\begin{gathered}
\frac{\partial \rho_{i}^{t}}{\partial t}=\frac{\tau}{L^{2}} D_{a} \frac{\partial^{2} \rho_{i}^{t}}{\partial x^{2}} \Rightarrow \tau=\frac{L^{2}}{D_{a}} \\
\rho_{i}^{t+1}=\rho_{i}^{t}+\frac{\Delta t}{\Delta x^{2}}\left(\rho_{i+1}^{t}-2 \rho_{i}^{t}+\rho_{i+1}^{t}\right)=\rho_{i}^{t}+\alpha\left(\rho_{i+1}^{t}-2 \rho_{i}^{t}+\rho_{i+1}^{t}\right) \quad i=2,3 \ldots N \\
\rho_{1}^{t+1}=\rho_{2}^{t+1} \\
\rho_{N}^{t+1}=\rho_{N-1}^{t+1}-\Delta x \frac{\dot{m}}{D_{a}}
\end{gathered}
$$

This numerical method converges to a solution only if $\alpha=\frac{\Delta t}{\Delta x^{2}}<\frac{1}{2}$, to obtain a good tradeoff between precision and speed we have used $\alpha=0.008$.

The diffusion coefficient $D_{a}$ is a key parameter in this problem but its value is unknown. To obtain this value we have compared the solution of the numerical method developed above with the experimental data relative to barium depletion depth in Ref 6 . The depletion depth is set at $50 \%$ of signal intensity on profiles of $\mathrm{BaO}$ concentration. If the numerical method is good we should find a set of $D_{a}$ values that follows an Arrhenius plot with activation energy similar to the one of barium oxide evaporation.

In Fig 5-6 we can see a comparison between numerical and experimental data and the exponential fit of diffusion coefficient's values. 


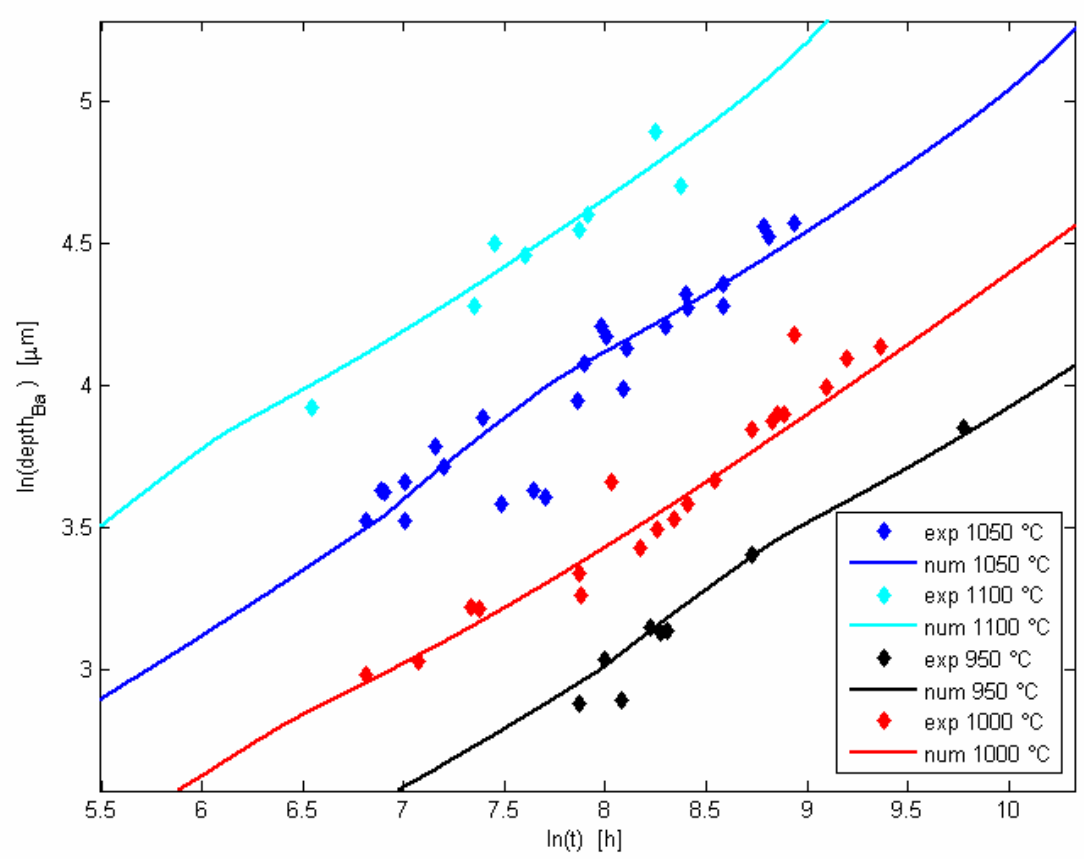

Figure 5. Comparison between numerical and experimental data ${ }^{6}$
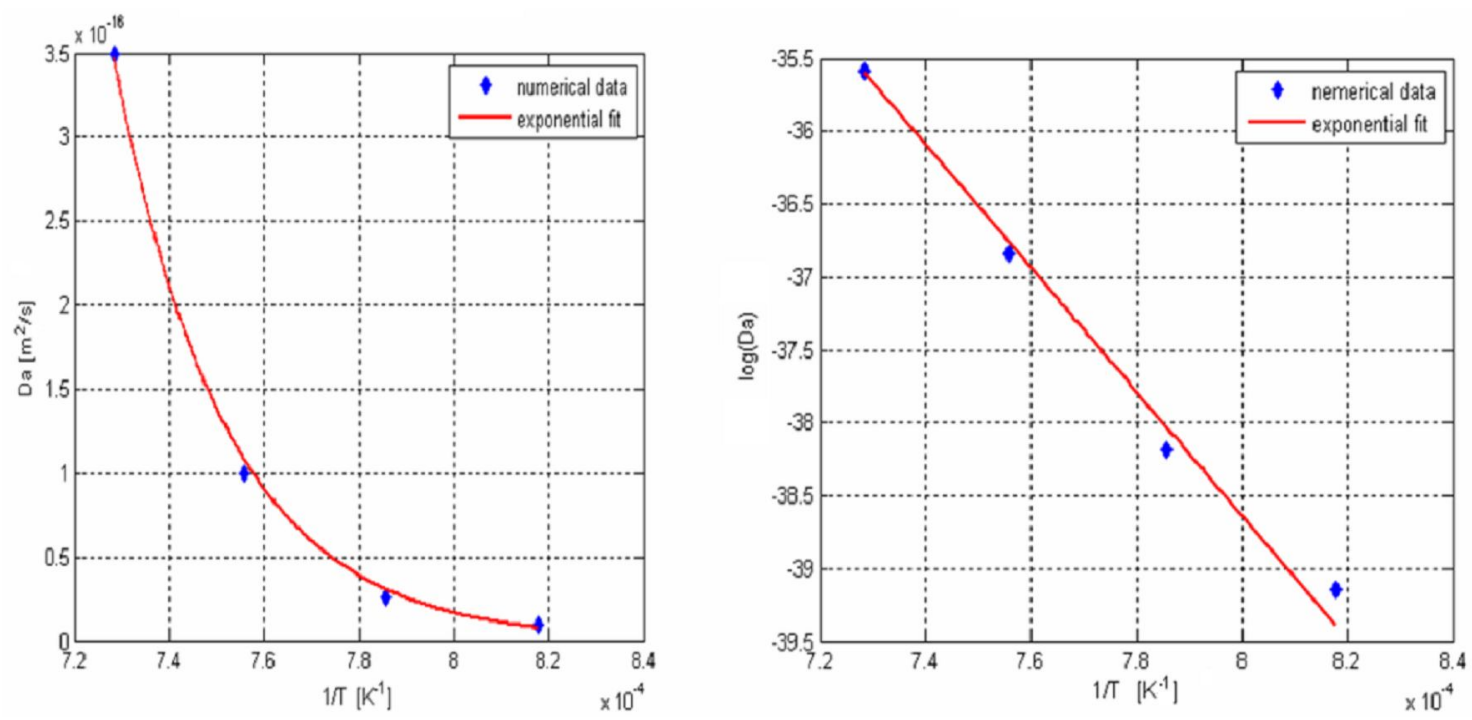

Figure 6. Diffusion coefficient trend

In Fig 7 we can see barium density profile inside the insert after at various time and temperature 

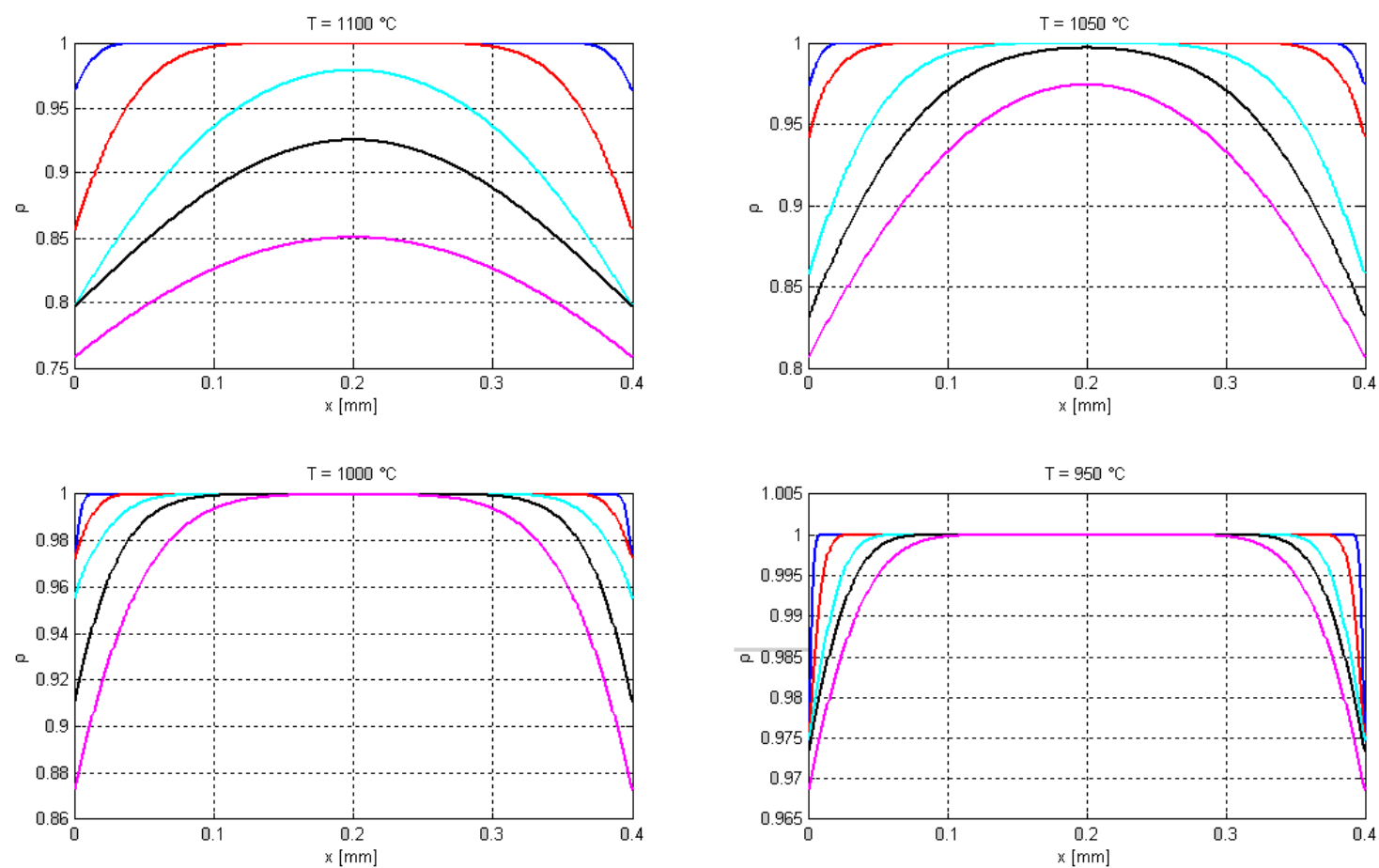

Figure 7. Barium oxide trend inside the insert at various time and temperature

As we can see from Fig 5-6 we have obtained a good match between experimental and numerical data and the $D_{a}$ values found are very well interpolated by an exponential fit. The activation energy derived from the interpolation is $E_{D a}=3.5 \mathrm{eV}$, as expected it is close to the energy of evaporation of Barium (4.32 eV) but lower because the diffusion involve just a "jump" of barium atoms from one vacancies to another and not their complete detachment from the barium crystalline structure; this confirms the accuracy of the model.

\section{3D Cylindrical Insert Model}

Once developed a one dimensional model we can easily generalize it and write a three dimensional cylindrical model.

Because of the cylindrical geometry we can reduce the 3D problem to a $2 \mathrm{D}$ problem on the r-z plane. This plane is sketched in Fig 8Errore. L'origine riferimento non è stata trovata.

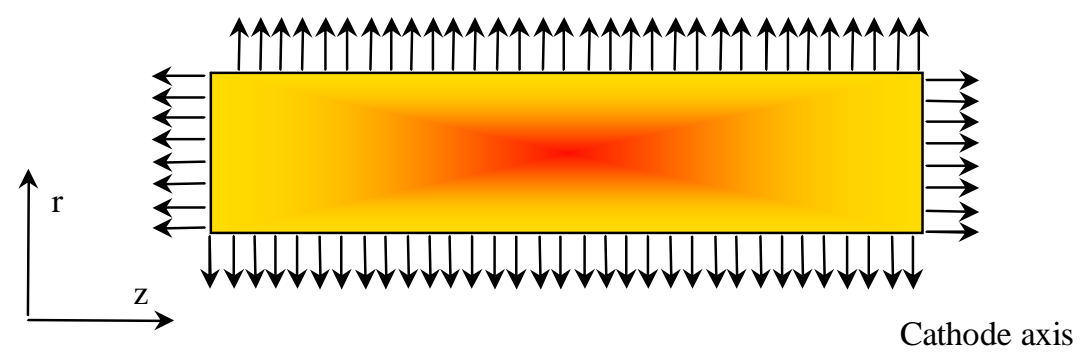

Figure 8 Cylindrical insert model

In a cylindrical reference frame, the governing equations is

$$
\frac{\partial \rho}{\partial t}-D_{a}\left(\frac{1}{r} \frac{\partial \rho}{\partial r}+\frac{\partial^{2} \rho}{\partial r^{2}}+\frac{\partial^{2} \rho}{\partial z^{2}}\right)-\frac{\partial \rho}{\partial z} \frac{\partial D_{a}}{\partial z}=0
$$

where the derivatives with respect to $\vartheta$ have been neglected because of the symmetry and where $D_{a}$ is now a function of $z$ because of the presence of a temperature along the insert length. 
The system can be non-dimensionalized using the insert thickness $d$ as characteristic length, the maximum value of the initial density as characteristic density, the maximum value of $D_{a}$ as characteristic diffusion coefficient and where the characteristic time is calculated as in Eq 5 .

It can be demonstrated that, using exactly the same method developed for the one dimensional case with a fixed space and time step, the algorithm still converges if $\alpha \leq 1 / 2$ and if the characteristic time is calculated using the maximum value of the diffusion coefficient.

Now the sensitivity of barium oxide depletion with temperature will be shown.

$\mathrm{BaO}$ depletion will be computed starting from a uniform and flat initial $\mathrm{BaO}$ content profile and assuming two different temperature profiles (arbitrarily to show some of the insert properties) along the insert ( $\mathrm{z}$ direction) without temperature gradient in the radial direction.

Both temperature profiles have the same mean value of $1038^{\circ} \mathrm{C}$.

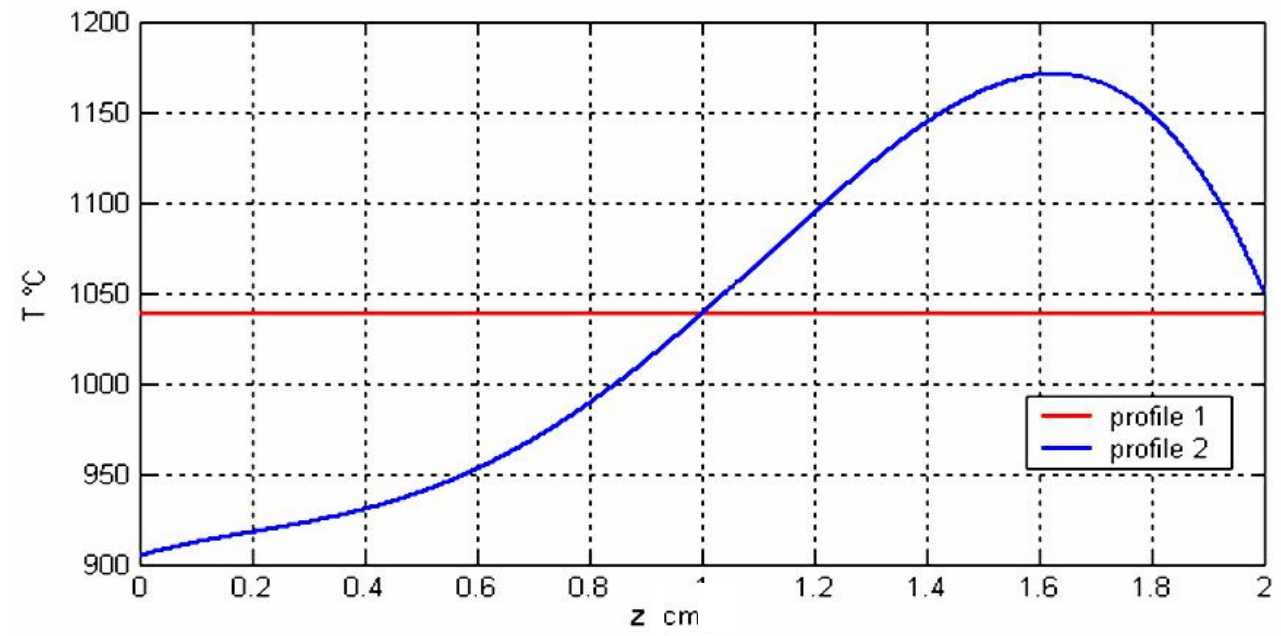

Figure 9 Temperature profiles with the same average $\mathrm{T}=1038{ }^{\circ} \mathrm{C}$

Evaporation as been assumed to occur only from the inner diameter and upstream surface.

The barium oxide depletion profile and the total barium available inside the insert are show in the next two pictures.
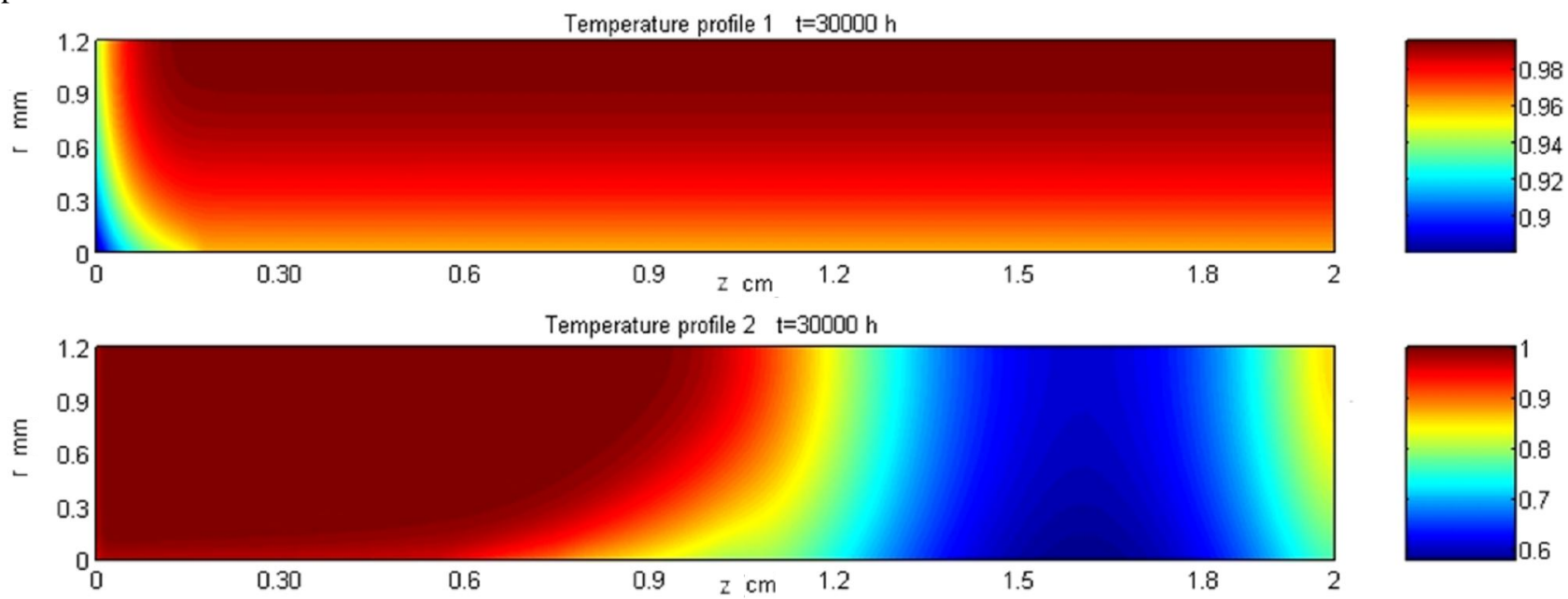

Figure 10 Barium oxide depletion profile after $30 \mathrm{kh}$ for different temperature profile 
AIAA-2007-5193

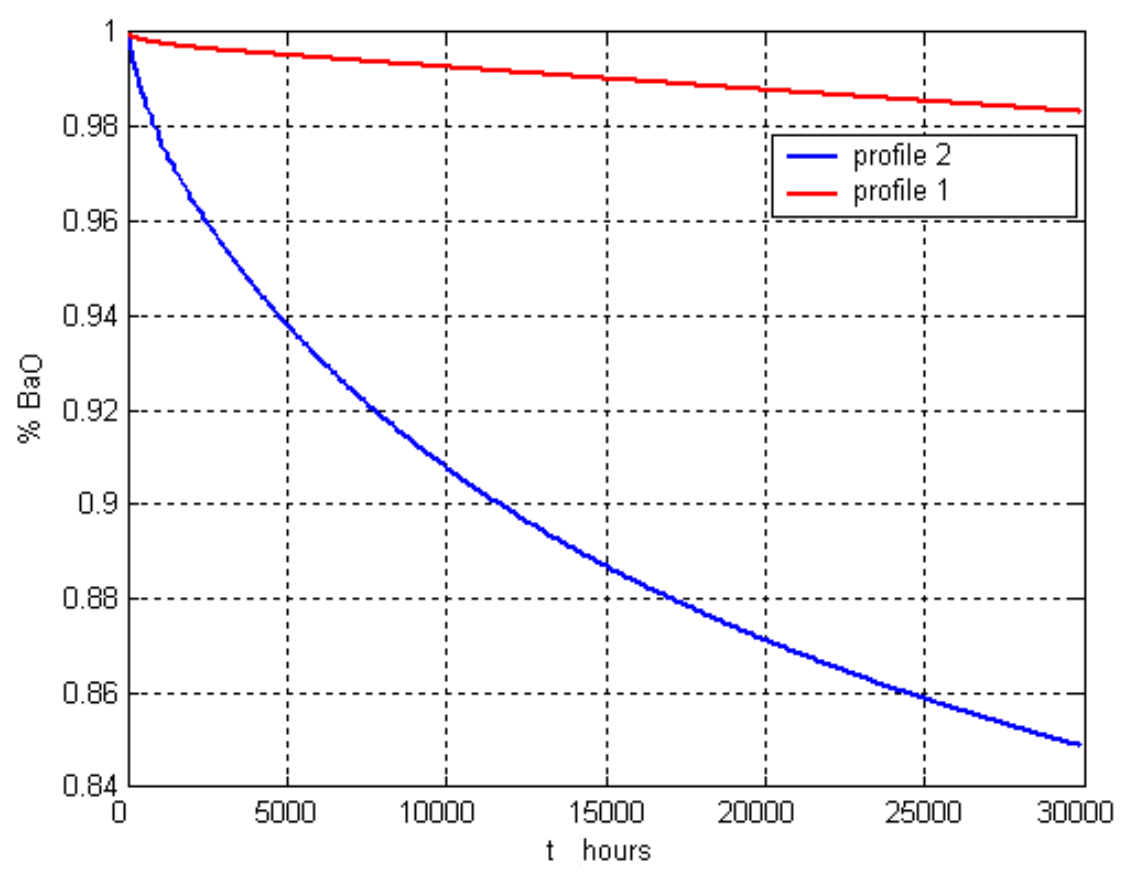

Figure 11 Total Barium oxide content inside the insert versus time for different temperature profile

As we can see from Fig. 10,11 the barium depletion profile and also the total depletion from the insert is totally different between the two temperature profiles.

As can be easily noted from Fig. 10 barium oxide depletion closely follows the temperature trend, higher depletion occurs where the temperature is higher because both evaporation and diffusion rate are exponentially proportional to temperature.

Looking at Fig. 11 we can see that with $T=1038{ }^{\circ} \mathrm{C}$, only $2 \%$ of the initial barium oxide content has been evaporated after 30 thousand hours, while with temperature profile 2, the evaporated barium is $15 \%$.

Hence can be seen how the knowledge of the temperature profile is far more important than the mean $T$ values , because a high temperature spot causes an high local evaporation rate and, at the same time, an high diffusion rate that allows more barium oxide to reach that spot and evaporate there.

\section{Conclusion and future work}

From the results obtained in this paper we can infer how barium depletion inside a hollow cathode insert depends strongly on the chemistry of the $\mathrm{BaO}-\mathrm{CaO}-\mathrm{Al}_{2} \mathrm{O}_{3}$ system and on the diffusion inside the insert. So we can state that it is not possible to obtain accurate results without taking into account these two aspects. We have also shown how the temperature profile along the insert is another key parameter to take into account and how analyze the insert using mean temperature brings to totally wrong results.

Future works will deal with how the evaporated barium oxide reacts with the insert surface generating those low work function compounds that are responsible for thermionic emission.

\section{Acknowledgments}

The Authors want to thank Prof Fulvio Stella for the help given in the numerical code writing, Dr. Paolo Gessini for the productive discussion and Prof Paolo Appendino for the help given in retrieving data relative to the $\mathrm{BaO}$ $\mathrm{CaO}-\mathrm{Al}_{2} \mathrm{O}_{3}$ ternary system.

\section{References}

${ }^{1}$ Gessini P., M. Coletti, N. Bevan, R. I. Marques, G. Michalareas, S.B. Gabriel, "Solar Electric Propulsion for Lunar Transfer", $1^{\text {st }}$ Hellenic European Student Space Science and Technology Symposium, October 2006

${ }^{2}$ Appendino P., "Ricerche sul Sstema Ternario Calce-Ossido di Bario-Allumina”, Ceramurgia, 1972, pp. 103-106. 
AIAA-2007-5193

${ }^{3}$ Lipeles R.A., Kan H.K.A, “Chemical Stability of Barium Calcium Aluminate Dispenser Cathode Impregnants”, Application of Surface Science 16, 1983, pp. 189-206

${ }^{4}$ Wolten G.M., "An Appraisal of the Ternary System $\mathrm{BaO}-\mathrm{CaO}-\mathrm{Al}_{2} \mathrm{O}_{3}$ ”, SD-TR-80-67, Space Division, Air Force System Command, Los Angeles, October 1980

${ }^{5}$ Resulhina T.N., Levitskii V.A., Frenkel M. Ya., Izvestiya Akademii Nauk SSSR, Neorgan. Mater. 2, 1966,pp. 325-331.

${ }^{6}$ Roquais J.M, Poret F., le Doze R., Ricaud J.L., Monterrin A., Steinbrunn A., "Barium Depletion Study on Impregnated Cathodes and Lifetime Prediction”, Applied Surface Science 215, 2003, pp. 5-17. 